\title{
HACIA LA CREACIÓN \\ DE UN MERCADO \\ DEL SUELO EN ESPAÑA
}

FELIO JOSÉ BAUZÁ MARTORELL*

Fecha de recepción: 7 de marzo de 2013.

Fecha de aceptación: 25 de junio de 2013.

I

DEL RESULTADO A LOS MEDIOS

Comenzado por el final, la foto fija de la política urbanística y de ordenación del territorio en España no puede ser más desalentadora. Basta una mirada superficial por la geografía para comprobar en toda su magnitud el consumo de territorio, la transformación del suelo, la destrucción de la costa y el litoral, la edificación en las laderas y cimas de los montes...

Pero más desesperante que la realidad estática, lo verdaderamente cruel es que toda esta degeneración se ha producido en los últimos treinta o cuarenta años, que es curiosamente cuando mayor intervención sobre el suelo ha existido por parte de los poderes públicos.

En efecto la legislación del suelo es relativamente reciente en nuestro país, de suerte que la primera Ley del Suelo data de 1956. Hasta entonces el legislador fue siempre ajeno a la edificación, y es precisamente hasta esas fechas y un poco más cuando el consumo de recursos naturales obedecía a la lógica y al sentido común. De hecho son los centros históricos de cualquier población los espacios más bellos, más ordenados y más deseados, al tiempo que nacieron de forma espontánea por el operador económico al margen de la regulación planificadora de la autoridad urbanística.

* Abogado, Doctor en Derecho y Profesor Asociado del Departamento de Derecho Público de la Universidad de las Islas Baleares. 
Por el contrario los extra radios de las ciudades y la ocupación de la costa han proliferado bajo la vigencia de leyes y reglamentos, estatales o autonómicos, planes generales, normas subsidiarias... extremo que supone una evidente contradicción y que obliga a reflexionar sobre cuáles son los errores cometidos. Lo mismo hay que decir de la viviendas y urbanizaciones ilegales, cuyo número resulta imposible de determinar. Sólo en la provincia de Málaga se estima que existen unas sesenta mil viviendas al margen del ordenamiento urbanístico, de las cuales ocho mil se sitúan en el municipio de Mijas; en la provincia de Sevilla se calcula que existen cincuenta y dos urbanizaciones legales, la mitad que en Madrid.

Cualquier intento de recopilar exhaustivamente la ingente normativa que regula el suelo es una tarea titánica por no decir imposible: la Ley estatal del Suelo, diez y seis leyes autonómicas del suelo (todas las Comunidades menos Baleares), leyes de suelo rústico o no urbanizable, ley patrimonio histórico, ley de patrimonio natural y biodiversidad (que deroga la Ley de Conservación de la Naturaleza del Estado, si bien subsisten todas las leyes autonómicas de conservación de la naturaleza), Ley de Costas, Ley de Montes y sus homónimas autonómicas, todas las leyes de medidas urgentes y desarrollo sostenible que se han aprobado en los últimos años, leyes de incendios forestales, la red Natura 2000 y los espacios declarados LIC (lugar de interés comunitario) o ZEPA (zona de especial protección para las aves), leyes de medidas ambientales, normativa en materia de recursos hídricos que afectan al subsuelo y al suelo, limitaciones de normas sectoriales en materia de carreteras, litoral, puertos y aeropuertos, reglamentaciones técnicas (Código Técnico de la edificación, Reglamento de Instalaciones Térmicas de los Edificios)... y a todo ello hay que añadir los instrumentos municipales de planeamiento (que tienen naturaleza reglamentaria): planes generales, normas subsidiarias, planes parciales, planes especiales y estudios de detalle.

Pues bien, todo este sobre dimensionamiento normativo no ha sido capaz de frenar un desarrollo urbanístico errático. Se han dictado febrilmente leyes y reglamentos, se han creado organismos públicos para vigilar y controlar la disciplina urbanística (observatorios, agencias...) y, pese a ello, la tozuda realidad es la que es: 
la de un crecimiento caótico y descontrolado, en muchos casos con daños irreversibles.

II

\section{DE LA INTERVENCIÓN IMPENITENTE}

El régimen del suelo es de vital importancia para dar cumplimiento a un principio rector de la política social y económica, la vivienda (art. $47 \mathrm{CE}$ ), así como para cualquier actividad productiva. Sin suelo no existe prácticamente nada. La Carta Europea de Ordenación del Territorio aprobada por la Conferencia Europea de Ministros de Ordenación del Territorio de 23 de mayo de 1983 la define como la «expresión espacial de la política económica, social, cultural y ecológica de toda la sociedad». ${ }^{1}$

No se olvide que el suelo afecta directamente a la actividad productiva y comercial: a día de hoy el suelo afecta a la vivienda, y no en vano las noticias dramáticas sobre desahucios de familias enteras son constantes; infinidad de pequeñas y medianas empresas han desaparecido por no poder pagar rentas en concepto de alquiler o las hipotecas de sus negocios; pero también el suelo afecta a los salarios y al empleo, dado que el empleador debe reducir gastos y despedir personal; incluso en época de bonanza económica el suelo afecta a la edad de emancipación de los jóvenes e incluso a la edad en que se tienen hijos, que se ha retrasado entre quince y veinte años (una generación) ${ }^{2}$ como consecuencia de los precios de la vivienda.

\footnotetext{
1 Citado en la Sentencia del Tribunal Constitucional 149/1991, de 4 de julio, en los recursos de inconstitucionalidad 1689/1988, 1708/1988, 1711/1988, 1715/1988, $1717 / 1988,1723 / 1988,1728 / 1988,1729 / 1988$ y 1740/1988, interpuestos contra la Ley 22/1988, de 28 de Julio, de Costas.

2 Jurídicamente el concepto de generación se ha situado en la tria genicula, los treinta y tres años, haciendo acopio en derecho administrativo del derecho canónico y en este caso concreto de la edad de Cristo. El profesor García de Enterría explica cómo en las concesiones administrativas se situó el límite de noventa y nueve años por ser interpretar que después de dos generaciones se perdía la memoria de las cosas. Y por ello el máximo de un título concesional era la generación presente y dos más. García de Enterría (1995), pp. 34-35.
} 
De ahí que el suelo no pueda ser desatendido por los poderes públicos en cuanto garantes del interés general y de los principios constitucionales. Otra cosa consiste en el alcance y los límites de esa intervención.

La intervención administrativa en materia de suelo se lleva a cabo en nuestro ordenamiento jurídico a través del planeamiento municipal. En los planes municipales el Ayuntamiento y la Consejería correspondiente deciden por dónde debe crecer el municipio, qué usos urbanísticos deben llevarse a cabo en cada polígono, y hasta la densidad de población en cada núcleo.

A nadie escapa que esta intensidad de intervención no es en modo alguno admisible. El planeamiento queda en manos de arquitectos y políticos, en algún caso aparecen los juristas, pero los economistas son los grandes olvidados en este procedimiento y tienen mucho que decir. ${ }^{3}$ Entre otras cosas, porque no hay que olvidar que, como recurso que es, el suelo se encuentra sometido a las leyes del mercado. Y resulta que el juego de la oferta y la demanda se ve literalmente entorpecido por la decisión política.

En efecto el grado de intervención es tal que el gobernante decide hasta el último detalle el diseño de la ciudad. No en vano el informe del entonces Tribunal de Defensa de la Competencia de 1993 titulado Remedios politicos que pueden favorecer la libre competencia en los servicios y atajar el daño causado por los monopolios dedica su epígrafe décimo a la competencia en el mercado del suelo y censura cómo la decisión errática del planificador dinamita el mercado del suelo hasta el punto de fragmentarlo y desvirtuar el precio de mercado del suelo.

El problema en España es que, en vez de fijar unas reglas generales de defensa de los intereses públicos, la autoridad urbanística va decidiendo todo hasta el extremo de poder determinar con el máximo detalle el uso de cada espacio. Al impedir a los propietarios decidir el uso del espacio, se segmenta el mercado del suelo, de tal forma que los distintos usos no compiten por la utilización del suelo. Es como si en vez de haber un mercado hubiera ochenta o cien mercados diminutos. Esta falta de competencia entre usos

3 Vid. Jacobs, J. (1969). 
alternativos, genera una mala asignación de recursos y da lugar a la aparición de rentas monopólicas. La compartimentación del mercado disminuye la oferta para cada uno de los usos y fuerza al alza los precios.

El problema de no permitir el juego de la competencia, es que, como el futuro no se corresponde siempre con lo previsto por la autoridad urbanística, se producen movimientos espasmódicos en cantidades y en precios. Así, en algunos casos, resultan terrenos sobrantes y en otros, como ha sucedido con las oficinas, faltó espacio y los precios se dispararon, porque la demanda de usos del espacio no se ajustó a lo que la autoridad urbanística había previsto.

Lo mismo sucede continuamente en el caso del suelo para vivienda donde coexisten terrenos sin edificar y precios altos. Es la paradoja del intervencionismo extremo: por un lado sobra terreno y por otro lado, y simultáneamente, los precios se disparan.

En España la única liberalización del suelo que se ha emprendido fue con la Ley de 1998. Pero esta liberalización se centró en desclasificar suelo; el razonamiento del legislador fue el siguiente: si existe más suelo urbano, su precio descenderá. No obstante, no se acometió la desregulación del sector del suelo; a día de hoy el mercado del suelo sigue siendo una ficción, sencillamente no existe y la causa no es otra que el intervencionismo impenitente.

\section{III \\ EL MERCADO DEL SUELO}

\section{Un mercado inexistente}

Libertad de empresa y planificación son dos institutos antagónicos. De hecho en la denominada Constitución económica los dos extremos son la libertad de empresa en el marco de la economía de mercado (art. $38 \mathrm{CE}$ ) y la planificación estatal de la actividad económica general (art. $131 \mathrm{CE}$ ).

Entre ambas opciones el legislador español se ha decantado por este segundo en cuanto al régimen jurídico y económico del suelo. 
Como idea, la planificación del suelo no es mala en sí. En un alarde de inocencia, el art. 131 CE justifica la planificación en el objetivo de "atender a las necesidades colectivas, equilibrar y armonizar el desarrollo regional y sectorial y estimular el crecimiento de la renta y de la riqueza y su más justa distribución». Lo que sucede es que en la práctica los efectos de la planificación del suelo son perversos por los motivos expuestos.

No se olvide en este sentido que el ideal planificador responde a la filosofía soviética, extinguida desde hace décadas por su fracaso fundamentalmente social y no menos económico. ${ }^{4}$ En el sistema político soviético ni existe la propiedad privada ni tampoco la iniciativa de los particulares. La anulación del emprendedor deja todo el espacio a la autoridad gubernativa, que decide manu militari la marcha del país.

El suelo en el sistema político continental de corte francés no dista de ese juego macabro. Para empezar el Estado desconfía del ciudadano, y no en vano cualquier actividad se encuentra sometida a autorización con carácter previo. Desde la Directiva de Servicios 2006/123/CE, conocida por el nombre del Comisario de Comercio que la impulsó, Sr. Bolkenstein, en algunos campos se sustituye la licencia previa por una declaración responsable o una comunicación previa. ${ }^{5}$ No obstante en materia de urbanismo esta Directiva no resulta aplicable por considerarse una razón imperiosa de interés general. ${ }^{6}$ De ahí que en urbanismo se siga exigiendo

4 Vid. El fracaso histórico del socialismo en Huerta de Soto, J. (2010). p. 21.

5 Bauzá Martorell, F.J. (2010).

6 Según el Considerando 40 de la Directiva, que se reproduce en el art. 4.8, el concepto de «razones imperiosas de interés general» al que se hace referencia en determinadas prescripciones de la presente Directiva ha sido desarrollado por el Tribunal de Justicia en su jurisprudencia relativa a los artículos 43 y 49 del Tratado y puede seguir evolucionando. La noción reconocida en la jurisprudencia del Tribunal de Justicia abarca al menos los ámbitos siguientes: orden público, seguridad pública y salud pública, en el sentido de los artículos 46 y 55 del Tratado, mantenimiento del orden en la sociedad, objetivos de política social, protección de los destinatarios de los servicios, protección del consumidor, protección de los trabajadores, incluida su protección social, bienestar animal, preservación del equilibrio financiero de los regímenes de seguridad social, prevención de fraudes, prevención de la competencia desleal, protección del medio ambiente y del entorno urbano, incluida la planificación urbana y rural, protección de los acreedores, garantía de una buena administración de 
la licencia previa con toda la burocracia - en muchos casos innecesaria- que ello comporta.

Por razones obvias debemos ser críticos con el sistema de la Directiva de Servicios y en especial en lo que concierne al urbanismo. En efecto Cholbi Cachá y Merino Molins entienden que el régimen de autorización previa queda con carácter residual a partir de la Directiva 2006/123/CE, salvo en los supuestos en que pueda existir una serie de riesgos o peligros por la falta de intervención a priori o, cuando entren en juego razones imperiosas de interés general. La cuestión de mayor calado estaría en qué tipo de actividad no reúne alguno de los ámbitos relacionados con los objetivos de orden público; salud pública, protección de los consumidores, protección del entorno urbano o del medio ambiente que harían por vía de «excepción» la necesidad, por razones imperiosas de interés general, de acudir a un régimen de autorización previa que, evidentemente, no sea discriminatorio en razón de la nacionalidad. ${ }^{7}$ De ahí que, incluso en este punto en que en apariencia se aprecia un avance, por el contrario en la realidad no nos alejamos de la ambigüedad normativa, que es al que da lugar a la inseguridad jurídica, tan perniciosa para la actividad económica. Y prueba de ello es que tanto el derecho positivo como la doctrina jurisprudencial hacen acopio de esta ambigüedad.

Así existen leyes autonómicas urbanísticas y de ordenación del territorio que - al amparo del Considerando 9 de la Directiva de Servicios excluyen por completo la declaración responsable ${ }^{8}$ mientras que otras sí lo permiten: Castilla La Mancha reserva

\footnotetext{
justicia, seguridad vial, protección de la propiedad intelectual e industrial, objetivos de política cultural, incluida la salvaguardia de la libertad de expresión de los diversos componentes (en especial, los valores sociales, culturales, religiosos y filosóficos de la sociedad), la necesidad de garantizar un alto nivel de educación, mantenimiento de la diversidad de prensa, fomento de la lengua nacional, conservación del patrimonio nacional histórico y artístico y política veterinaria.

7 Cholbi Cachá, F. y Merino Molins, V. (2010).

8 Ley 10/1990, de 23 de octubre, de Disciplina Urbanística de Baleares; Ley 7 / 2002, de 17 de diciembre, de Andalucía; Ley 5/1999, de 8 de abril, de Castilla y León; Ley de Ordenación del Territorio y Urbanismo de Asturias aprobada por Decreto Legislativo 1/2004, de 22 de abril; la Ley 3/2009, de 17 de junio, de Aragón; Ley 2/2001, de 25 de junio, del Suelo de Cantabria; Ley Foral 35/2002, de 20 de diciembre, Ordenación del Territorio y Urbanismo de Navarra; Ley 16/2005, de 30 de diciembre, de
} 
determinados actos tasados a licencia urbanística (art. 165 del Decreto Legislativo 1/2010, de 18 de mayo) y deja el resto de actos sujetos al régimen de comunicación previa. Cataluña va más allá al enumerar también de forma exhaustiva qué actos se someten a autorización previa (Decreto Legislativo 1/2010, de 3 de agosto), remitiendo a las ordenanzas municipales la posibilidad de sustituir la licencia por la comunicación previa.

En sede jurisprudencial la situación no es distinta: la Sentencia del Tribunal Superior de Justicia de Madrid, Sala delo Contencioso Administrativo, Sección 2. a , de 1 de octubre de 2009 (rec. $616 / 2009$ ) confirma el cese de una actividad en un despacho de abogados por incumplimiento de normas urbanísticas a pesar de la Directiva de Servicios, mientras que la Sentencia del mismo Tribunal, Sala y Sección de 17 de febrero de 2011 (rec. 701/2009) por el contrario establece que la Ordenanza del Ayuntamiento de Madrid de 29 de junio de 2009 (BOCAM de 6 de julio de 2009) queda fuera del ámbito de aplicación de la Directiva. ${ }^{9}$

\section{Las trabas del mercado del suelo}

\section{a) Burocracia administrativa}

La tramitación de cualquier licencia urbanística, si se escapa de los cauces ordinarios, supone un auténtico calvario para el promotor de incalculables dimensiones. Dadas las competencias concurrentes entre las distintas Administraciones, un expediente tiene que discurrir por órganos especializados (comisiones de medio ambiente), departamentos específicos (carreteras, litoral, costas...) que convierte a la tramitación en el mito de sísifo: vuelve a empezar una y otra vez, modificando continuamente el proyecto duante años con el consiguiente coste económico.

La maraña administrativa no se explica sino por el número de procedimientos existentes, que a su vez se modifican caprichosa-

la Comunidad Valenciana; Ley 15/2001, de 14 de diciembre, de Extremadura; Ley 5/ 2006, de 2 de mayo, de La Rioja; Ley 9/2001, de 17 de julio, de Madrid.

9 Hernández López, J. (2012). 
mente. Si las reglas son pocas y claras (y no por ello menos contundentes), el particular conoce el coste y la duración de un proyecto, y puede optar por intervenir en el mercado o no. Por el contrario la situación actual impide tener conocimiento del devenir del proyecto y de su final. De ahí que el incumplimiento de la normativa - fruto del empacho de regulación - sea una opción para el promotor, y de ahí los casos de corrupción.

Pero la corrupción no siempre es tal; dicho de otra forma, no todo incumplimiento de la legislación constituye un delito urbanístico o contra la ordenación del territorio. En ocasiones la cantidad de normas que recaen sobre una actuación de un particular es tal, que se alcanza una situación de bloqueo. Y este enroque se trata de deshacer con soluciones imaginativas. Así no es infrecuente encontrarse con licencias urbanísticas provisionales o en precario, que no es más que dar forma jurídica a una imposibilidad legal de edificar.

Melián y Calzada explican este fenómeno en el carácter estático del planeamiento urbanístico, cuando la realidad es mucho más dinámica. ${ }^{10}$ En efecto desde una perspectiva jurídica Soriano García plantea que - al ser el grado de intervención tal- el planificador decide hasta el más mínimo detalle la calificación y la clasificación del suelo al margen de la iniciativa particular; a continuación el promotor decide emprender un proyecto, si bien se encuentra en un laberinto administrativo que le obliga a demorar su actividad durante años, de manera que su idea se convierte en obsoleta. ${ }^{11}$ Ahí radica la distorsión de la oferta y la demanda: cuando la oferta consigue ver la luz, la demanda — si no el mismo plan- ha variado.

De ahí que una necesidad de lege ferenda sea la de formular un inventario de procesos y simplificar al máximo el régimen jurídico del suelo.

10 Melián, G. y Calzada Álvarez, G. (2012), p. 53.

11 Soriano García, J.E. (1995). 


\section{b) Nefanda política}

Más importante que lo anterior, la política debe alejarse del suelo. Santamaría Pastor vierte el símil de que los medicamentos deben situarse fuera del alcance de los niños y el urbanismo de la política.

Como consecuencia de la discrecionalidad y de la ambigüedad con que se redactan las normas, no es infrecuente que el plan o las normas subsidiarias se modifiquen para atender casos singulares. Incluso se hace uso del instrumentos de la rectificación de errores materiales para exceptuar por conveniencia una norma urbanística, extremo que se encuentra próximo - sino dentro- de la corrupción.

En otras ocasiones el agente político deniega - pese al carácter reglado de la licencia urbanística- una licencia al promotor que solicita edificar con arreglo a derecho, sólo por una causa ideológica, obligando al particular a recurrir en vía contenciosa y modificando paralelamente el planeamiento para que, cuando el juzgado o tribunal estimen el recurso, alegar una imposibilidad material de ejecutar la sentencia. Más allá que eso, es posible la concesión ilegal de una licencia, y una vez dictada sentencia que ordena el derribo, el Ayuntamiento suspende con total desfachatez la ejecución para modificar el plan. No en vano Soriano García denuncia una nueva inmunidad del poder consistente en la inejecución de sentencias condenatorias a la Administración basándose en el ius variandi como fundamento jurídico para alterar el planeamiento. ${ }^{12}$

Esta práctica ha sido objeto de atención por el Tribunal Constitucional, que ha concedido amparo al particular cuyo derecho fundamental a la tutela judicial efectiva (art. 24 CE) ha sido conculcado. ${ }^{13}$

La inejecución de sentencias condenatorias a la Administración es una lacra social y una carga de profundidad para el estado de Derecho: existe un título jurídico concreto que sorprendentemente se pretende desconocer, y ello no lo hace cualquier sino la propia Administración.

\footnotetext{
12 Soriano García, J.E. (2010).

13 Rodríguez Fernández, I. (2009).
} 
Por último aparecen configuraciones de ciudades a la carta: ciudades deportivas, ${ }^{14}$ ciudades del ocio, ciudades del juego ${ }^{15} \ldots$ todo ello fruto de presiones sociales, económicas y políticas, que demuestran que la normativa urbanística es cambiante y que no obedece a criterios generales. También aparece una mezcolanza entre lo público y lo privado cuando determinadas obras o servicios se licitan incluyendo como mejoras una instalación para el municipio (polideportivos, parques, centros sociales o culturales...).

\section{IV \\ LA COMPETENCIA EN EL MERCADO DEL SUELO}

No se puede crear un verdadero mercado del suelo si no se introduce el factor de la competencia, y para ello habrá que desburocratizar y despolitizar el régimen jurídico del suelo.

Urge superar la actual rigidez del urbanismo. Los poderes públicos deben devolver al ciudadano la iniciativa que con la legislación del suelo le usurparon, lo cual no significa en modo alguno que el urbanismo pueda convertirse en salvaje. La Administración no puede renunciar a la regulación del suelo; en su Camino de servidumbre, Friedrich Hayek admite que la planificación es inevitable (capítulo cuarto). ${ }^{16}$ Pero debe hacerlo con reglas claras y permitiendo que sea el promotor el que introduzca la competencia en el suelo. De esta manera los usos del suelo responderán a una demanda efectiva y real, y los tiempos para ejecutar las decisiones responderán a cánones factibles.

El legislador ha querido situar expresamente el suelo al margen del mercado, cuando alrededor del mismo giran intereses muy fuertes. Tal es así que hasta proliferan plataformas y lobbies de afectados por viviendas ilegales que claman por una amnistía

\footnotetext{
14 Vid. Martínez Gutiérrez, R. (2012), pp. 147-188.

$15 \mathrm{Vid}$. la crítica — que no podemos menos que compartir que formula López Ramón (2012), pp. 11-14.

16 Hayek, F. Camino de servidumbre. Unión Editorial. Trad. de José Vergara Docel. Prólogo de Carlos Rodríguez Braun. Introducción de Bruce Caldwell.
} 
urbanística. ${ }^{17}$ Como el hecho de que un porcentaje elevadísimo de los casos de corrupción giran en torno al urbanismo.

Desde la perspectiva económica, la legislación -en este caso, urbanística- o es eficiente o no es. A diferencia de otros sectores que han experimentado con éxito la desregulación, por el contrario el régimen jurídico del suelo sigue sometido a un derecho dictado y un derecho impuesto. Al decir de Huerta de Soto «el deseo voluntarista de "ordenar" la sociedad vía mandatos coactivos es esencialmente generador de desorden", 18 entre otras cosas por la normativa no ha incorporado el factor de la eficiencia y el Estado no puede suplantar totalmente a la sociedad civil sin equivocarse. De ahí que desde la óptica política haya que hacer propia la teoría del raynerismo anglosajón: hacer retroceder las fronteras del Estado.

Por poner un ejemplo reciente: el Real Decreto 235/2013, de 5 de abril regula el procedimiento básico para la certificación de eficiencia energética de los edificios. ¿Acaso un asunto que afecta a la economía doméstica del consumidor (pagar menos por el consumo de energía) debe estar regulado coactivamente? ¿Es posible que haya que obligar a los propietarios de viviendas a contar con un certificado de eficiencia energética cuando son los primeros interesados en que su vivienda sea los menos costosa posible? Pues en nuestro país el legislador concibe algo tan elemental como un deber de obligado cumplimiento para el titular de un inmueble con todo un régimen sancionador detrás (art. 18 del Real Decreto citado).

El error que los poderes públicos han ido rectificando en los últimos quince años consiste en suprimir los mandatos imperativos por el desarrollo de un marco normativo en el que, articulado en torno a la competencia, los operadores han ido interviniendo

17 Bajo el paraguas de las medidas urgentes y el desarrollo sostenible, no son pocas las Administraciones tanto estatal como autonómicas que tienen que rendirse ante los hechos consumados de viviendas y urbanizaciones ilegales que se consolidan en el tiempo como consecuencia de la nefasta gestión pública del suelo. La reciente Ley del Parlamento de Cantabria 4/2013, de 20 de junio (BOC de 3 de julio) es un claro ejemplo al llevar por título el régimen jurídico de las autorizaciones provisionales de edificaciones o actuaciones preexistentes.

18 Huerta de Soto, J., op. cit., p. 112. 
libremente con espíritu emprendedor. En palabras de Martínez Meseguer «la ley no debería perseguir crear un determinado orden, sino poner las bases para que el propio orden espontáneo crezca y evolucione en un contexto de libertad». ${ }^{19}$

El problema en este punto consiste en que el suelo ha sido el gran olvidado del proceso desregulador, quizás porque los poderes públicos no han prestado atención a la variable económica del suelo y a la existencia de un mercado de suelo, enfocando la regulación bajo el prisma de la intervención más absoluta.

Un ejemplo del intervencionismo caótico es el de la Sociedad Pública de Alquiler (SPA), creada en 2006 bajo un mandato socialista con el objetivo de estimular el mercado de alquiler y contrarrestar el precio de la vivienda. Lo que olvidó de manera garrafal el Ministerio de la Vivienda en esa fecha fue que el alquiler no es libre en nuestro país como consecuencia de una falta de legislación que otorgue seguridad jurídica y material al propietario arrendador, que puede perfectamente encontrarse con un inquilino que no satisface las rentas, al que cuesta horrores (tiempo y recursos monetarios) desahuciarle, que durante todo el procedimiento encima debe abonarle sus gastos de consumos de servicios básicos, que puede haber abandonado la vivienda y sin embargo el propietario no puede acceder hasta que lo considera el Juzgado, y, por último, que finalmente no puede repercutirle gasto algún por haber desaparecido y no tener domicilio conocido. Frente a este escenario irracional, al poder público no se le ocurre otra medida que crear un organismo público que medie entre arrendador y arrendatario, sin modificar ni una sola norma que hace posible este absurdo; de ahí el estrepitoso fracaso de la SPA, que a día de hoy se encuentra en disolución. Todo lo contrario de lo que debería haberse hecho: crear un marco jurídico que impida estas situaciones de injusticia y que elimine el temor del propietario a arrendar su inmueble; con una legislación estable, no haría falta ninguna medida de fomento del alquiler. Por un criterio meramente económico, el propietario de una vivienda vacía la ofrecerá sin pestañear al mercado para obtener una renta. En caso contrario, si la normativa no acompaña, por mucho que exista un organismo público

19 Martínez Meseguer, C. (2009), p. 14. 
que haga de mediador, pueden que las rentas no monetarias de paz y tranquilidad sean más convincentes que una renta monetaria que puede convertirse en un infierno.

Recientemente y de forma parcial el Real Decreto Ley 19/2012, de 25 de mayo, de medidas urgentes de liberalización del comercio y de determinados servicios - que por cierto en sus únicos dos títulos mezcla dos regulaciones tan dispares como el impulso del comercio y la exportación de material de defensa- en su art. 3.3 suprime la necesidad de licencia urbanística para obras de acondicionamiento de los locales para desempeñar la actividad comercial cuando no requieran de la redacción de un proyecto de obra de conformidad con la Ley 38/1999, de Ordenación de la Edificación. ${ }^{20}$ Pero más allá de este supuesto residual, la autorización administrativa sigue estando vigente en toda su extensión. Se trata de un primer paso, tímido todavía, pero que debe ir cogiendo forma y extendiéndose a todos los ámbitos, entre otras cosas porque el legislador reconoce en el art. 1.1 de esta norma «cargas y restricciones administrativas existentes que afectan al inicio y ejercicio de la actividad comercial». En consecuencia, estas cargas son predicables de cualquier actividad, no sólo la del comercio minorista.

Habrá que superar este pánico del legislador e introducir la competencia en el suelo, crear un verdadero mercado con unas reglas claras y con un control efectivo y ejemplarizante de la Administración, que es algo que - como se ha visto- a día de hoy deja mucho que desear. Como cualquier sector económico que es, en el mercado del suelo los poderes públicos deben crear un marco regulador que haga posible que la sociedad civil decida con el juego de la oferta y la demanda, así como el factor tiempo, los usos y destinos del suelo. La Administración debe establecer los parámetros urbanísticos (alturas, tipología, coeficientes de edificabilidad, índices de ocupación...) y a partir de ahí los promotores deben actuar conforme a las normas generales y objetivas.

La experiencia histórica es más que notoria: si a lo largo de miles de años los núcleos de población han crecido espontáneamente (siendo como son los más atractivos) y por el contrario en las

20 Ortega Montoro, R.J. (2012), pp. 1636-1644. 
últimas décadas, a raíz de la regulación coactiva hasta el más mínimo detalle, el territorio se ha maleado hasta límites insospechados, la conclusión no puede ser más contundente: regresemos a la espontaneidad, volvamos a la libertad del individuo dentro de un marco jurídico general, sin renunciar a la intervención, pero con un nivel que permita al promotor y al consumidor de suelo generar oferta y demanda. El territorio - al decir de Azpitartetiene un orden propio fruto de la interacción de los ciudadanos, ${ }^{21}$ un orden que no puede ser sustituido por el orden artificial de la Administración, un orden que los poderes públicos deben respetar y potenciar.

Por razones obvias el cambio no puede ser radical. Existe una cultura administrativa alrededor del suelo, tanto en España como en países de nuestro entorno, que obligan a que el cambio sea gradual. El cambio debe comenzar por las instituciones, las cuales —al decir de Douglas North - tienen mayor incidencia en el cambio económico que la propia tecnología; ${ }^{22}$ y del cambio institucional habrá que pasar al normativo.

En definitiva hace falta acercar la Economía al Derecho. El análisis económico del Derecho, en este caso urbanístico, no supone siempre una retirada de normas, sino un cálculo económico y técnico de su oportunidad y eficiencia. ${ }^{23}$

\section{REFERENCIAS BIBLIOGRÁFICAS}

AzPitARTE, J. (2012): «El derecho urbanístico español. Introducción a una visión crítica desde la perspectiva de la Escuela Austriaca de Economía». Procesos de Mercado. Revista Europea de Economía Política, vol. IX, n.. 1, primavera.

BAUZÁ MARTORELL, F.J. (2010): «Declaración responsable y comunicación previa. Consideraciones críticas del procedimiento administrativo a raíz de la Ley Ómnibus». Diario La Ley, n.. 7419,8 de junio.

\footnotetext{
21 Azpitarte, J. (2012), p. 79.

22 North, D. (1990).

23 Soriano García, J.E. (1993).
} 
Cholbi Cachá, F. y Merino Molins, V. (2010): Comentario crítico sobre la Directiva de Servicios y de las Leyes 17 y 25/2009 en aplicación de la misma: especial incidencia en el ámbito de las licencias urbanísticas y de actividad. El Consultor de los Ayuntamientos y de los Juzgados, n.ํㅜ 7. Sección Actualidad. Quincena del 15 al 29 de abril de 2010. Editorial La Ley.

GARCÍA DE ENTERRÍA, E. (1995): Dos estudios sobre la usucapión en Derecho Administrativo. Madrid.

HAYEK, F. (2008): Camino de servidumbre. Unión Editorial. Trad. de José Vergara Docel. Prólogo de Carlos Rodríguez Braun. Introducción de Bruce Caldwell.

Hernández López, J. (2012): A vueltas con la Directiva de Servicios y las licencias municipales. El Consultor de los Ayuntamientos y de los Juzgados, n.. ${ }^{\circ}$. Sección Colaboraciones. Quincena del 30 de marzo al 14 de abril de 2012. Editorial La Ley.

Huerta de Soto, J. (2010): Socialismo, cálculo económico y función empresarial. Unión Editorial. Madrid.

Jacobs, J. (1969): La Economía de las Ciudades. Edicions 62. Barcelona.

López RAMÓN, F. (2012): «Ciudades privadas para el juego». Revista española de Derecho Administrativo, n.o 156. OctubreDiciembre.

Martínez GutiéRRez, R. (2012): «El sorprendente mundo del fútbol y el Derecho. A propósito de algunas operaciones urbanístico-deportivas. Revista de Administración Pública», n.ำ 188. Madrid. Mayo-Agosto.

Martínez Meseguer, C. (2009): Teoría evolutiva de las instituciones. Unión Editorial. Madrid.

Melián, G. y Calzada Álvarez, G. (2012): «Freedom, creativity and the future of cities». Procesos de Mercado. Revista Europea de Economía Política, vol. IX, n.. 1, primavera.

NorTH, D. (1990): Institutions, Institutional Change and Economic Performance. Cambridge University Press.

Ortega Montoro, R. J. (2012): Desmontando el sistema de licencia municipal en el ámbito de las actividades comerciales y de servicios (y urbanístico): el Real Decreto Ley 19/2012, de 25 de mayo. El Consultor de los Ayuntamientos y de los Juzgados, n.. $14 / 2012$. 
RodríGUEZ FERNÁNDEZ, I. (2009): Demolición de obras ilegales, restablecimiento de la legalidad y tutela judicial efectiva. Reflexiones a propósito de la Sentencia del Tribunal Constitucional 22/2009, de 26 de marzo. Revista general de Derecho Administrativo, n. ${ }^{\circ}$ 22. Iustel.

SORIANO GARCía, J.E. (1995): Hacia la tercera desamortización (Por la reforma de la Ley del Suelo). Prólogo de Pedro Schwartz. Marcial Pons. Madrid.

- Urbanismo y corrupción. Medidas cautelares, única solución. El Notario del Siglo XXI, n.․․ 29. Enero-Febrero 2010.

- Desregulación, privatización y Derecho Administrativo. Real Colegio de España. Bolonia, 1993. 